\title{
Celebrity and Politics
}

\author{
Samantha Majic ${ }^{1}$, Daniel O'Neill, and Michael Bernhard
}

\section{The Presidential Address}

$\square$

ur first issue each year begins with the publication of the Presidential Address from the previous year's APSA Annual Meeting. This year we have the pleasure of publishing "What Good Can Political Science Do? From Pluralism to Partnerships" by Rogers Smith. Rogers Smith was the President of the American Political Science Association for 2018-2019 and is the Christopher H. Browne Distinguished Professor of Political Science at the University of Pennsylvania. He works in the areas of constitutional law and American political thought, with a focus on how race, ethnicity, and gender affect citizenship. He has been elected to the American Academy of Arts and Sciences (2004), the American Academy of Political and Social Science (2011), and the American Philosophical Society (2016). His many notable publications include Political Peoplehood: The Roles of Values, Interests, and Identities (University of Chicago Press, 2015), Still a House Divided: Race and Politics in Obama's America (with Desmond King, Princeton University Press, 2011), Stories of Peoplehood: The Politics and Morals of Political Memberships (Cambridge University Press, 2003), The Unsteady March: The Rise and Decline of Racial Equality in America (with Philip Klinkner, University of Chicago Press, 1999), Civic Ideals: Conflicting Visions of Citizenship in U.S. History (Yale University Press, 1997), Citizenship without Consent: the Illegal Alien in the American Polity (with Peter Schuck, Yale University Press, 1985), and Liberalism and American Constitutional Law (Harvard University Press, 1985; rev. ed., 1990), several edited collections, and innumerable articles and book chapters.

"What Good Can Political Science Do?" begins by taking inventory of the state of the world and the discipline. The picture is not pretty. Dictatorship is on the march globally and public support for political science is declining, with the value neutral pursuit of knowledge under assault in a highly politicized and polarized national environment. The issue of whether the discipline produces anything useful has resurfaced as it does periodically. Questions arise as to whether we have become too specialized, abstract, and insular to contribute the kind of knowledge that is of use in our current political debates or in solving our many nagging problems. Smith calls for greater practical engagement of the discipline with worldly questions. We need to make our results more relevant to practical political questions and synthesize our knowledge so that it helps society focus on "big picture" questions. For instance, we must use what we know about identity formation to understand the resurgence of nationalism and the hardening of deep social divisions. He also calls for more civically engaged research to both strengthen our understanding of community and to contribute more directly to it. Finally, he urges the discipline to recommit to teaching as one of its central missions and to focus on ways to improve the transmission of knowledge and society's understanding of politics. He believes that in this way political science as a discipline can make a contribution to resolving malaise rather than becoming a casualty of the antipathy it generates.

\section{Celebrity and Politics}

In airports and grocery store lines, you've likely passed displays of US Weekly, Star, Hello!, In Touch, and People. They scream out with headlines such as "Jenn and Angie: DUMPED AT THE SAME TIME" or "Beyonce to Jay-Z: IT'S OVER!"; ' you might thumb through or even purchase these magazines. Sometimes, you read them more often than you read this important scholarly journal. But we are not here to judge. Instead, this special issue of Perspectives on Politics places what some may dismiss as a guilty pleasure-celebrities-at the forefront of political science analysis. Why? Because these individuals_-defined broadly as persons well known for their work in entertainment, sports, and a range of other fields-are increasingly visible players in American and global politics, doing everything from endorsing electoral candidates to protesting policy developments. And with their massive fan bases and media reach, celebrities have a vast platform to advance their issues and views, and they are often granted access to national and international governing bodies such as the U.S. Congress and the United Nations. When they engage in political activities, then, they potentially shape opinions and outcomes, but they are not subject to traditional mechanisms of democratic accountability such as elections. 
In light of this, we agree with Dan Brockington that "the study of celebrity is not a shallow or trivial exercise. Critics may bemoan the intellectual content of much celebrity news, but that does not make it off-limits to the academe" (Brockington 2014, 88). To expand the study of celebrities within our particular academic realm - political science-in the fall of 2017 we issued a call for papers to consider celebrity and politics, broadly defined. We received nearly forty submissions and publish here a wideranging group of articles representing a diverse range of scholars, subfields, and methodological approaches. This introduction contextualizes these articles by first defining "celebrity" and situating celebrities' political activity historically. Next, we sketch the broad contours of their contemporary political work, considering here what existing scholarship tells us about celebrities' power to shape political debates and policy outcomes, among other things. In closing, we summarize the articles in this special issue, which reflect Perspectives' particular approach to political science: by prizing interesting work on a topical issue from multiple fields, they offer new and innovative ways to think of celebrity and political power both theoretically and empirically.

\section{Context}

In the age of social media, almost anyone may achieve celebrity status. However, scholars from a range of fields indicate that specific features define this category of person, the first and most general of which is that they are widely known. The term "celebrity" has roots in the Latin "celebritas" (fame) and "celeber" (frequented), and thus a person of celebrity is known for his "known-ness" (Boorstin 2012) and has a name that "needs no further identification" (Mills 2000, 71-72). Generally, this "known-ness" comes from an individual's musical talent, acting skills, or athletic prowess, but in an ever-expanding media environment, it can come from any number of activities, as indicated by the rise of celebrity chefs, fashion designers, and even politicians, among others. ${ }^{3}$

However, known-ness is not an inherent quality but a process (Drake and Higgins 2012), and so another general feature of celebrity is its production through the ongoing interaction of texts (e.g., television shows), producers (e.g., publicists), and audiences (those who encounter and use their images) over time (Gamson 1994, Rojek 2001). By extension, then, ongoing public and media recognition is another key element of celebrity (Marshall 2014). Effectively, "media exposure is the oxygen that sustains the contemporary celebrity," meaning that celebrities are widely followed and recognized in the mainstream media (television, newspapers), social media (Instagram, Facebook, etc.) and other online media (e.g., the blogosphere) (Drake and Miah 2010, 55).

Additionally, celebrities are also a commercial phenomenon in that their presence or the activity for which they are known is commodified and marketized in some way. With the rise of social media technologies, almost anyone may become known and recognized, and so fame alone is more democratized and less valuable (Turner 2014). What sets celebrities apart is their capacity to use their fame to draw attention to and promote the consumption of a particular product, be it a television show, album, sporting match, or other consumer good that is associated with their activities, talents, or images. In short, this commercial element is what distinguishes celebrities from the merely famous.

Altogether, celebrity is a highly contingent and unstable status that can change overnight (Drake and Miah 2010, 52; see also Driessens 2013). This contingency is also related to fans' preferences and national context. Regarding the former, soccer fans, for example, may recognize Lionel Messi and Cristiano Ronaldo (the subject of the article by Chris Anderson and his coauthors in this issue) as celebrities, whereas American football fans may not. And while celebrity status is often associated with individuals from the Global North, as Zainab Alam's piece in this issue indicates, the fact that individuals such as Nollywood ("Nigerian Hollywood") actor Genevieve Nnaji has starred in over eighty Nollywood movies and has over six million followers on Instagram indicates that celebrity (and the production thereof) is not the sole purview of Hollywood and the American media industries.

In addition to their work on screen, in the ring, or on stage, celebrities develop and deploy their fame by engaging in politics. While Donald Trump's election to president of the United States may be the most recent and high-profile example, scholars have documented celebrities political participation regarding a range of issues including (but not limited to) conservation and LGBT rights; both Democratic and Republican electoral campaigns and get-out-the-vote efforts; and international diplomacy and development (Meyer and Gamson 1995; Payne, Hanlon, and Twomey 2007; Nolan and Brookes 2013; Choi and Berger 2010; Biccum 2011; Brockington 2014). But this political engagement did not occur overnight; instead, a range of factors facilitated this, one of which was structural shifts in the entertainment industry. Prior to the mid-twentieth century, celebrity entertainers' work in politics was constrained by their contractual agreements with Hollywood studios, which were on the defensive against government accusations of communism (Gamson 1994, Demaine 2009). During the 1960s, however, the Hollywood studio system declined and mounting social turmoil in the United States set the stage for celebrity entertainers to become politically active; many embraced this enthusiastically such as actors Jane Fonda, Charlton Heston, and Paul Newman (Demaine 2009).

Alongside the decline of the Hollywood studio system, the "mediatization" of society also fueled celebrities' 
political ascendance. According to Jesper Stromback and Frank Esser, the invention of the television, followed by computers and the introduction of the internet, cell phone technologies, multi-channel cable networks, and personal electronic devices have facilitated a social change process (mediatization) in which the media has become deeply integrated and increasingly influential in different spheres of society (Stromback and Esser 2014; see also van Elteren 2013 and Turner 2014). In this context, a growing number of images, voices, and sounds compete for viewers' attention, and celebrities, who are often charismatic performers and highly skilled communicators, are especially adept at capturing media attention for various issues and for presenting themseleves as concerned spokespeople for a range of issues (Demaine 2009).

Alongside mediatization, the sites and patterns of political power and engagement have also shifted in ways that facilitate celebrities' political participation. Technological developments in travel, computing, and communication, alongside processes of economic globalization and the rise of migration in response to wars and environmental disasters, have lessened the significance of national borders while increasing the range of nongeographical constituencies emerging from gender, race, the environment, global trade, etc. (Urbinati and Warren 2008; Saward 2009). In response, a wide array of local, national, and international groups such as the United Nations, the World Bank, globalized corporations, nonprofits, and advocacy groups have emerged to attend to their non-residential/geographical concerns (Saward 2009). While these issue-based and policy driven networks of organizations and stakeholders may give new voice to underrepresented groups, they have also enhanced participation among the corporate elite and highly organized political advocacy groups that lack the traditional, electoral representative accountability to those affected by decisions (Urbinati and Warren 2008; Strolovitch 2007).

In this context, powerful individuals have ascended to potentially and significantly influence the political agenda. Of course, this "power elite" (Mills 2000), from the Robber Barons of the early twentieth century to the hedge fund Titans of today, have always had an outsized capacity to engage in and influence politics and policy. But now these individuals and the highly organized groups representing their interests contribute record amounts to political campaigns and step in to ameliorate public problems at unprecedented rates (Goss 2016). As a result, political authority is increasingly delegated to private, elite actors in both U.S. and global governance as leaders of governing bodies increasingly rely on them to deal with an increasingly complex world and to even serve as proxies for the masses (Partzsch 2017; Brockington 2014).

As Lena Partzch documents, celebrities are among the most newly visible and significant individuals in this constellation of elite, non-state agents (Partzsch 2017; see also Goss 2016). Their power rests on financial resources, relationships with other (often wealthy) elites who seek their company, and most significantly, their "celebrity (or fame) capital" - an achievement of public exposure that affords them valuable political, economic, cultural, or social-psychological currency that they can spend to draw attention to socio-political issues and to promote change, among other things (Gunter 2014; see also Driessens 2013). This currency is strengthened by their performances, which create an emotional response among their adoring fans (Rojek 2001). As a result, then, not only do many believe that Angelina Jolie is heroic on screen, as an adventurer (in Lara Croft: Tomb Raider) or as a crusading journalist (in A Mighty Heart), they also often believe that she is heroic in real life. In short, because celebrities are uniquely positioned to capitalize on and mobilize their resources and media expertise, they can engage in politics and convince the public that they have the answers to the problems they face (Bang 2007; Hart and Tindall 2009; Brockington 2014). Often, "the prestige-generating power of success makes celebrities special and gives them the power to exert normative influence" (Lindenberg, Joly, and Stapel 2011, 103).

But once they have captured public attention about an issue, celebrities' capacity to directly shape how people think or act is more difficult to discern. If one looks to research in marketing and communications, there is evidence that celebrity endorsements may shape public behavior. As Johannes Knoll and Jörg Matthes found in their recent meta-analysis of studies that experimentally tested the impact of celebrity endorsements on endorsed objects, while there was "a zero overall effect of celebrity endorsements on consumers' responses," they found some strong effects under some conditions (Knoll and Matthes 2017, 66). For example, they found that male celebrity endorsers had stronger endorsement effects on consumers than their female counterparts, and that actors elicited stronger celebrity endorsement effects when compared to other types of celebrities such as models, musicians, athletes, or television hosts.

Of course, a celebrity's endorsement of and its subsequent impact on perfume or cereal sales is not equivalent to her endorsement of a particular political cause or position, and research about celebrities' influence on political opinions shows mixed results, drawn often from small-n, regionally specific experimental studies. For example, Craig Frizzell conducted an experiment to test whether a statement by Bono (of U2 fame) regarding a fictional foreign policy crisis would influence public opinion more than one from a traditional political elite. $\mathrm{He}$ found that despite predictions in existing literature that the public should agree with celebrity statements, "in the case of foreign policy the respondents were more likely to adopt the non-celebrity position than the celebrity position" (Frizzell 2011, 319). The main reason for this was 
that "respondents did not generally consider Bono to be a trusted source of information." However, these results were also a function of party identification: "For Republicans and Independents, the respondents were more likely to adopt the position of the non-celebrity than the celebrity. While this may be due to those respondents assuming that the non-celebrity was ideologically similar to themselves, [the results] indicate that celebrities cannot increase support in comparison to other elites even when the respondents disagree with the elites" (Frizzell 2011, 322).

Beyond public opinion, celebrities' power to shape electoral preferences and outcomes is also mixed. For example, Andrew Pease and Paul R. Brewer tested whether the "Oprah effect" - the media mogul and celebrity's massive fan base and considerable influence endorsing products ranging from books to cars-would translate to electoral influence. Specifically, they considered her 2007 endorsement of Barack Obama for the Democratic presidential nomination and whether voters would use this as an informational cue for evaluating candidates. Their experiment, conducted shortly after the announcement (where participants read different news stories about her endorsement and then answered questions about their opinions about Obama), revealed that Oprah's endorsement did not actually influence the extent to which participants held favorable opinions toward Obama or saw him as likable. However, they found that reading about the endorsement "did lead participants to see Obama as more likely to win the nomination and to say that they would be more likely to vote for him" (Pease and Brewer 2008, 386).

In the policy realm, celebrities' power to shape outcomes is also unclear. Scholars have documented that elected officials increasingly invite celebrities to offer testimony and other feedback on policy, even when they have little professional, scholarly, or other expertise with the issue. Linda Demaine, for example, documented that "during the years 1980 through 2004, celebrity entertainers testified before the United States Congress on social issues unrelated to their professions 507 times in front of 539 congressional committees and subcommittees . . . [and] the frequency of these appearances more than doubled between the first five years of the study, 198084 , and the last five years of the study, 2000-04" (Demaine 2009, 90). Furthermore, their testimony was quite narrowly focused: while they addressed a broad range of social issues, these were mainly within the realm of health and crime, and the political orientation expressed in celebrity entertainers' testimony leaned "toward the liberal side of the spectrum" (Demaine 2009, 96).

But even as celebrities may now occupy prominent positions in the contemporary polity, their actual political power to shape policy outcomes and resource distribution remains unclear. For example, despite claiming to know nothing about the complicated and controversial issue of human trafficking until her daughter, then age 11, told her that she learned about it in school and wanted to do something about it, actor Jada Pinkett Smith testified before the Senate Foreign Relations Committee on July 17, 2012 to support the reauthorization of the Trafficking Victims Protection Act (TVPA). Although the TVPA was reauthorized, it is impossible to attribute this to Pinkett Smith's testimony. As scholars have documented, numerous celebrities have testified before Congress about this issue over many years, and a confluence of factors such as the growth of the anti-human trafficking movement and the issue's ascendance in popular discourse and culture have also shaped this legislation and its repeated reauthorization (see, e.g,. Bernstein 2012; Peters 2015).

If we do attribute public opinion and policy change to celebrities, even to a minor degree, questions arise whether we should be concerned about this influence. On the one hand, some have argued that celebrities' political activity is (overall) benign, given that they often take up uncontroversial issues and positions in an effort to please their fans and maintain their celebrity brand, to say nothing of their product and other endorsements (Vesey 2015). On the other hand, there are legitimate reasons to be concerned about their political activities, even if their impacts are difficult to discern. After all, celebrities' high profiles afford them access to prominent political spaces like the U.S. Congress, and they are often less knowledgeable about the issues they take on, prone to dramatization, and unaccountable for the policy solutions they propose (Choi and Berger 2010; van Elteren 2013). Regarding human trafficking, Dina Haynes (2014) found that celebrities who testified on it before the U.S. Congress tended to focus on dramatic stories of the sex trafficking of women and girls by criminal gangs and non-Western/nonwhite men, and they commonly promoted law-and-order solutions that emphasized punishment over prevention. And they did this even though labor trafficking into other sectors of the economy is arguably more prevalent, and large numbers of men, boys, and transgender persons are also at risk (UNODC 2016). As a result, Haynes argues, "celebrity activism is not significantly advancing the eradication of human trafficking and may even be doing harm by diverting attention from aspects of the problem and solution that sorely require attention" (Haynes 2014, 25).

Altogether, it is clear that celebrities are active in political life, speaking for various issues and populations in the ever-expanding media-scape, while legislators increasingly grant them access to governing bodies. Given that the study of politics is centrally concerned with power, this special issue builds on existing celebrity and politics scholarship to question and assess their roles and impacts in the polity. Certainly, the articles in this issue do not resolve debates about whether celebrities actually 
influence political discourse and policy outcomes, among other things, but they do break new ground as they interrogate celebrity power from a variety of theoretical and methodological perspectives.

\section{The Special Issue Articles}

We begin this issue with pieces that offer theoretical and conceptual tools for examining the relationship between celebrity and political power. Given that celebrities are highly visible in political life but also subject to criticism, Alfred Archer, Amanda Cawston, Benjamin Matheson, and Machteld Geuskens's "Celebrity, Democracy, and Epistemic Power" considers celebrity involvement in politics and its potential implications for democratic theory and practice. They argue that celebrities possess epistemic power, understood in terms of the ability to influence what others believe, think, or know, and to enable and disable others from exerting epistemic influence by either giving credence to or discrediting others. Although many individuals may possess this power, celebrities' epistemic power is noteworthy because it comes from their ability to attract attention, despite their lack of relevant political or other issue expertise. Archer et al. argue further that existing democratic theory fails to recognize celebrities' epistemic power and its risks, including its illegitimate ability to set political agendas, relative immunity from familiar checks on power, and its undermining of democracy's epistemic qualities. However, they conclude that celebrities' power may be mitigated by, for example, demanding that the media correct misinformation that celebrities often promote.

Celebrities have exercised significant epistemic power in the humanitarian realm, and to help scholars specify and further interrogate this activity, Lisa-Ann Richey and Dan Brockington's "Celebrity Humanitarianism: Using Tropes of Engagement to Understand North/South Relations" understands celebrities' humanitarian work as transferring issue interpretations from the perspective of the Global North to the Global South. Arguing that studies of celebrity humanitarianism must go beyond focusing on individual celebrities and must be interpreted through the broader cultural, political, and economic systems of which they are a part, they offer a series of tropes through which celebrity humanitarianism is frequently conducted. This heuristic typology refocuses celebrity research away from its Northern emphasis and helps scholars identify the politics and political solutions advanced by current forms of celebrity humanitarianism.

Building from these more theoretical pieces, the next two articles consider celebrities' exertions of power and the implications thereof. In "Caffeinated Solutions as Neoliberal Politics: How Celebrities Create and Promote Partnerships for Peace and Development," Alexandra Budabin studies George Clooney's and Ben Affleck's efforts to promote peace and development in South Sudan and the Eastern Congo through their respective partnerships with Nespresso and Starbucks. Using these cases, she examines how celebrities exert power and influence through their mobilization of financial and political capital and their circulation of narratives promoting market-based approaches to humanitarianism and development. She argues that Clooney's and Affleck's efforts reinforce neoliberal politics, which have significant impacts for democracy. Not only do they increase the access and influence of elite private actors in the humanitarian realm, despite their lack of expertise and other formal qualifications, they also promote public-private partnerships that often escape public scrutiny.

While Budabin's piece considers the power and potential influence of celebrities from the Global North, Zainab Alam's "Do-It-Yourself Activism in Pakistan: The Case of Celebrity Qandeel Baloch" shifts our attention to the Global South. In Alam's study of the late Pakistani socialmedia celebrity Qandeel Baloch, her feminist analysis of those social-media postings reveals that Baloch deployed them to create new forms of public space and to challenge dominant social norms and political practices. Through what Alam terms "do-it-yourself activism," Baloch critiqued long-established norms governing gender, class, and sexuality, and she expanded the boundaries of national belonging in Pakistan to include women like herselfnamely, culturally rebellious women of limited economic means. This article indicates that while celebrities may indeed reinforce hierarchies and elite politics, they may also use their position to illuminate and politicize injustices.

Building on these articles, which theorize and illustrate celebrity exertions of political power, the following four articles variously study the impact of celebrities' political activity on various populations. To begin this examination, Chris Anderson, Luc Arrondel, André Blais, JeanFrançois Daoust, Jean-François Laslier, and Karine Van der Straeten's "Messi, Ronaldo, and the Politics of Celebrity Elections: Voting for the Best Soccer Player in the World" offers an innovative examination of celebrities' power to move opinion. Using historical election results and an original survey of soccer fans to assess players' success in the Ballon d'Or (the high profile election of the world's best player), they find that players from top teams in striker positions (like Lionel Messi and Cristiano Ronaldo) are significantly more likely to win the Ballon d'Or, all of which suggests a clear and growing hierarchy in the competition for soccer celebrity. In making this argument, Anderson et al. expand the study of celebrity and politics to an ostensibly non-political election, which is important because "in an age when a reality TV star can be elected President of the United States, understanding what drives people's affinity for one icon over another matters" (p. 92). 
In addition to considering how celebrities may shape individual opinions, Nyron Crawford, Christopher Towler, and Robert Bennett's "Shut Up and Play: Black Athletes, Protest Politics and Black Political Action" examines the extent to which celebrities can mobilize populations to act, particularly those who are underrepresented in mainstream American society. Using the 2017 Black Voter Project Pilot Study to examine the relationship between race, celebrity, and social movements, they ask whether Colin Kaepernick's protest of police violence mobilized black Americans to political action. Focusing specifically on African American political engagement in the 2016 election, they find that African Americans who strongly approve of Kaepernick's protest engaged in politics at elevated rates, even after accounting for alternative explanations. Moreover, approval for Kaepernick also moderated other forces rooted in group identity, such as identification with the Black Lives Matter movement. In the end, they argue that Kaepernick and the protest movement he leads offer a powerful mobilizing force for African Americans.

In addition to potentially influencing large portions of the population, celebrities also reach and shape the work of journalists. Here, Amber Boydstun and Regina Lawrence's "When Celebrity and Political Journalism Collide: Reporting Standards, Entertainment, and the Conundrum of Covering Donald Trump's 2016 Campaign" explores how the press covered Donald Trump's 2016 presidential campaign. While earlier research predicts that he would have received "clown coverage"- that is, derisive, dismissive press coverage due to his career in reality television and lack of conventional political experiencehis fame, wealth, and campaign's entertainment value challenged this. Drawing from qualitative interviews with journalists and other political insiders and a content analysis of news coverage of Trump at key points throughout the campaign, they argue that a collision of entertainment-infused politics with traditional journalism practices challenged the press's ability to cover the campaign coherently. Ultimately, the press responded to this dilemma by giving Trump as much clown-like coverage as it did serious coverage through the primary and the general election.

The final article turns to consider how celebrities' political activities may potentially impact a celebrity's own status. In “Don't Republicans Tweet Too? Using Twitter to Assess the Consequences of Political Endorsements by Celebrities," Jan Zilinsky, Cristian Vacarri, Joshua A. Tucker, and Jonathan Nagler consider the risks that celebrities take when talking about politics on social media. Through an analysis of approximately 230,000 tweets from eighty-three celebrities who chose to endorse presidential candidates, the authors assessed whether celebrities pay a political penalty for discussing presidential candidates, and whether celebrities behave similarly to other campaign surrogates by "going negative." By documenting how often celebrities with distinct political preferences tweeted about Donald Trump, Bernie Sanders, and Hillary Clinton, they find that followers of opinionated celebrities do not withhold engagement when they become politically vocal and often go negative. And in a departure from previous research that indicates the public is more interested in celebrity gossip than serious news, they find that political content from celebrities is actually more popular than their typical lifestyle tweets in a number of cases.

\section{Final Thoughts on Celebrity and Politics}

Certainly, the articles in this issue are not the final, definitive publications on the topic of celebrity and politics; instead, they advance a large and growing body of scholarship from a range of scholarly fields. Altogether, we hope this special issue will spark more scholarly consideration of celebrities in political science, and indeed the pieces here point to directions for future research. While much research has considered celebrities in North America and parts of Europe, it is clear that more work is needed regarding the political activities and impacts of celebrities from the Global South. We also need to expand the range of methods for testing celebrities' actual impact on the public, broadly defined. But for now, we thank the authors for their contributions and the many reviewers who played such an important role in helping them sharpen their work.

\section{Other Content in This Issue}

We publish two other items in this issue, an additional article and a reflection. The article, "Accountability by the Numbers: Introducing a New Transitional Justice Dataset 1946-2016," is by Genevieve Bates, Ipek Cinar, and Monika Nalepa, and as the title suggests, it provides an overview of the most ambitious dataset for the study of transitional justice generated to date. Its novel facets include a time-series cross-national setup and the inclusion of both post-conflict and post-authoritarian cases in the same dataset. The authors develop three new measures to qualify transitional justice issues relating to personnel-severity, urgency, and polarization. At the same time they build up their own measures from data collected at a highly granular level, allowing other researchers who do not share their conceptual priors to use the data to build their own measures as well. They close the piece with some simple regressions to test whether transitional justice measures obstruct the efforts of authoritarian elites to preserve their power following episodes of democratization.

Finally, the issue also includes a reflection by Peter Hall: "The Electoral Politics of Growth Regimes." In a wide-ranging account, Hall discusses how the economic and social policies used by developed democracies to pursue 
economic growth were constrained by and evolved in response to electoral concerns. He traces this over the period of immediate postwar prosperity (1950-1975), the subsequent era of liberalization (1980-2000), and the contemporary era of the knowledge-based economy. The account shows how policy is not only a product of the development of the economy and technology, but of new and emergent electoral cleavages created by electoral strategies that tip the balance of power to specific actors at specific points in time. The piece concludes with a consideration of the new possibilities inherent in the current period of knowledge-based economic development.

\section{Bigger, Better Perspectives}

For the anacharonistics, luddites, and antediluvians among you who are physically holding the copy that you are reading, you may sense something different about this issue of Perspectives. From this issue onward, we have expanded from 296 to 322 pages. Previously we have devoted 148 pages to the introduction, articles, and reflections, and the same allocation to the book reviews. We have now added twenty-six pages (174 total) to the front end, while keeping the book review section at its current size. This will allow us to publish approximately two more articles or reflections in each issue. Keep those submissions coming. With some extra space, perhaps the rate of acceptance will go up.

\section{Notes}

1 Samantha Majic, Associate Professor of Political Science at the John Jay College of the City University of New York, served as Guest Editor for this Celebrity and Politics special issue. Samantha conceived of the project, wrote the call for papers, and served as the lead editor on all submissions to the special issue. The editors wish to express our gratitude for her diligent work and inspired intellectual leadership.

2 Sample article headlines from In Touch, July 17, 2014.

3 For a discussion of celebrity politicians, see Street 2012.

\section{References}

Bang, Henrik. 2007. "Parties in the Swing: Between Democratic Representation and Communicative Management." Unpublished manuscript, Department of Political Science, University of Copenhagen.

Bernstein, Elizabeth. 2012. "Carceral Politics as Gender Justice? The 'Traffic in Women' and Neoliberal Circuits of Crime, Sex, and Rights." Theoretical Sociology 41(3): 233-59.

Biccum, April. 2011. "Marketing Development: Celebrity Politics and the 'New' Development Advocacy." Third World Quarterly 32(7): 1331-46.

Boorstin, Daniel J. 2012. The Image : A Guide to PseudoEvents in America. 50th anniversary ed. New York: Vintage Books.
Brockington, Dan. 2014. "The Production and Construction of Celebrity Advocacy in International Development." Third World Quarterly 35(1): 88-108.

Choi, Chong Ju and Ron Berger. 2010. "Ethics of Celebrities and Their Increasing Influence on 21st Century Society." Journal of Business Ethics 91(3): 31318.

Demaine, Linda. 2009. "Navigating Policy by the Stars: The Influence of Celebrity Entertainers on Federal Lawmaking." Journal of Law and Politics 25(2): 83-143.

Drake, Philip and Michael Higgins. 2012. "Lights, Camera, Election: Celebrity, Performance and the 2010 Uk General Election Leadership Debates.” British Journal of Politics and International Relations 14(3): 375-91.

Drake, Philip and Andy Miah. 2010. "The Cultural Politics of Celebrity." Cultural Politics 6(1): 49-64.

Driessens, Oliver. 2013. "Celebrity Capital: Redefining Celebrity Using Field Theory." Theory and Society 42(5): 543-60.

Frizzell, Craig. 2011. "Public Opinion and Foreign Policy: The Effects of Celebrity Endorsements." Social Science Journal 48(2): 314-23.

Gamson, Joshua. 1994. Claims to Fame: Celebrity in Contemporary America. Berkeley: University of California Press.

Goss, Kristin. 2016. "Policy Plutocrats: How America's Wealthy Seek to Influence Government." PS: Political Science and Politics 49(3): 442-48.

Gunter, Barrie. 2014. Celebrity capital: assessing the value of fame. New York: Bloomsbury.

Haynes, Dina F. 2014. "The Celebritization of Human Trafficking." Annals of the American Academy of Political and Social Science 653(1): 25-45.

Knoll, Johannes and Jörg Matthes. 2017. "The Effectiveness of Celebrity Endorsements: A Meta-Analysis." Journal of the Academy of Marketing Science 45(1): 5575.

Lindenberg, Siegwart, Janneke F. Joly and Diederik A. Stapel. 2011. "The Norm-Activating Power of Celebrity: The Dynamics of Success and Influence." Social Psychology Quarterly 74(1): 98-120.

Marshall, P. David. 2014. Celebrity and Power: Fame in Contemporary Culture. 2nd ed. Minneapolis: University of Minnesota Press.

Meyer, David and Josh Gamson. 1995. "The Challenge of Cultural Elites: Celebrities and Social Movements." Sociological Inquiry 65(2): 181-206.

Mills, C Wright. 2000 [1956]. The Power Elite. Rev. ed. New York: Oxford University Press.

Nolan, David and Stephanie Brookes. 2013. "Populism in Theory and Practice: Analysing Celebrity Politics." Media Asia Research 40(4): 373-83.

Partzsch, Lena. 2017. "Powerful Individuals in a Globalized World." Global Policy 8(1): 5-13. 
Payne, J. Gregory, John P. Hanlon, and David P. Twomey III. 2007. "Celebrity Spectacle Influence on Young Voters in the 2004 Presidential Campaign: What to Expect in 2008." American Behavioral Scientist 50(9): 1239-46.

Pease, Andrew and Paul R. Brewer. 2008. "The Oprah Factor: The Effects of a Celebrity Endorsement in a Presidential Primary Campaign." International Journal of Press/Politics 13(4): 386-400.

Peters, Alicia. 2015. Responding to Human Trafficking: Sex, Gender, and Culture in the Law. Philadelphia: University of Pennsylvania Press.

Rojek, Chris. 2001. Celebrity. London: Reaktiob Books.

Saward, Michael. 2009. "Authorisation and Authenticity: Representation and the Unelected." Journal of Political Philosophy 17(1): 1-22.

Street, John. 2012. "Do Celebrity Politics and Celebrity Politicians Matter?" British Journal of Politics and International Relations 14(3): 346-56.

Strolovitch, Dara Z. 2007. Affirmative Advocacy : Race, Class, and Gender in Interest Group Politics. Chicago: University of Chicago Press.

Stromback, Jesper and Frank Esser. 2014. "Mediatization of Politics: Transforming Democracies and Reshaping
Politics." In Mediatization of Communication, ed. Knut Lundby, 375-403. Boston: De Gruyter Mouton.

t'Hart, Paul and Karen Tindall. 2009. "Leadership by the Famous: Celebrity as Political Capital." In Dispersed Democratic Leadership: Origins, Dynamics, and Implications, ed. Paul 't Hart, John Kane, and Haig Patapan, 255-278. Oxford: Oxford University Press.

Turner, Graeme. 2014. Understanding Celebrity. 2d ed. Los Angeles: SAGE.

United Nations Office on Drugs and Crime (UNODC). 2016. Global Report on Trafficking in Persons. Vienna: United Nations Office on Drugs and Crime. https:// www.unodc.org/documents/data-and-analysis/glotip/ 2016_Global_Report_on_Trafficking_in_Persons.pdf Urbinati, Nadia and Mark E. Warren. 2008. "The Concept of Representation in Contemporary Democratic Theory." Annual Review of Political Science 11(1): 387-412.

van Elteren, Mel. 2013. "Celebrity Culture, Performative Politics, and the Spectacle of 'Democracy' in America." Journal of American Culture 36(4): 263-83.

Vesey, Alyxandra. 2015. "Putting Her on the Shelf: Pop Star Fragrances and Post-Feminist Entrepreneurialism." Feminist Media Studies 15(6): 992-1008. 


\section{Statement of Mission and Procedures}

Perspectives on Politics seeks to provide a space for broad and synthetic discussion within the political science profession and between the profession and the broader scholarly and reading publics. Such discussion necessarily draws on and contributes to the scholarship published in the more specialized journals that dominate our discipline. At the same time, Perspectives seeks to promote a complementary form of broad public discussion and synergistic understanding within the profession that isessential toadvancing scholarship and promoting academic community.

Perspectives seeks to nurture a political science public sphere, publicizing important scholarly topics, ideas, and innovations, linking scholarly authors and readers, and promoting broad reflexive discussion among political scientists about the work that we do and why this work matters.

Perspectives publishes work in a number of formats that mirror the ways that political scientists actually write:

Research articles: As a top-tier journal of political science, Perspectives accepts scholarly research article submissions and publishes the very best submissions that make it through our double-blind system of peer review and revision. The only thing that differentiates Perspectives research articles from other peer-reviewed articles at top journals is that we focus our attention only on work that in some way bridges subfield and methodological divides, and tries to address a broad readership of political scientists about matters of consequence. This typically means that the excellent articles we publish have been extensively revised in sustained dialogue with the editors to address not simply questions of scholarship but questions of intellectual breadth and readability.

"Reflections" are more reflexive, provocative, or programmatic essays that address important political science questions in interesting ways but are not necessarily as systematic and focused as research articles. These essays often originate as research article submissions, though sometimes they derive from proposals developed in consultation with the editor in chief. Unlike research articles, these essays are not evaluated according to a strict, doubleblind peer review process. But they are typically vetted informally with editorial board members or other colleagues, and they are always subjected to critical assessment and careful line-editing by the editor and editorial staff.

Scholarly symposia, critical book dialogues, book review essays, and conventional book reviews are developed and commissioned by the Associate and Book Review Editor, based on authorial queries and ideas, editorial board suggestions, and staff conversations.

Everything published in Perspectives is carefully vetted and edited. Given our distinctive mission, we work hard to use our range of formats to organize interesting conversations about important issues and events, and to call attention to certain broad themes beyond our profession's normal subfield categories.

For further details on writing formats and submission guidelines, see our website at http://www.apsanet.org/ perspectives/ 